\title{
SARANA OLAHRAGA INTERAKTIF DI JATINEGARA
}

\author{
Natasha Monica ${ }^{1)}$, JM. Joko Priyono Santoso ${ }^{2)}$ \\ 1)Program Studi S1 Arsitektur, Fakultas Teknik, Universitas Tarumanagara, natashamonica08@gmail.com \\ 2) Program Studi S1 Arsitektur, Fakultas Teknik, Universitas Tarumanagara, jokop@ft.untar.ac.id
}

\begin{abstract}
Abstrak
Tawuran menjadi sebuah permasalahan yang ada di kehidupan sosial, yang dapat dikategorikan sebagai kenakalan remaja. Isu kenakalan remaja pada masyarakat saat ini semakin bertambah, hal ini menyebabkan keresahan pada masyarakat. Lingkungan, tempat tinggal, dan teman dalam pergaulan berpengaruh besar dalam pembentukkan jati diri serta perkembangan diri. Kenakalan remaja perlu ditangani serta perlu dilakukan upaya pencegahan, hal ini diperlukan untuk menghindari dampak yang lebih luas yang dapat mengancam keamanan masyarakat. Dengan menggunakan teori kenakalan remaja menurut Dr. Kartini Kartono dalam meneliti bentuk kenakalan remaja dan penanggulangan kenakalan remaja. Peneliti menggunakan metode perancangan Disprogramming untuk penggabungan beberapa program sesuai kebutuhan masyarakat.
\end{abstract}

Kata Kunci: kenakalan remaja; tempat ketiga

\begin{abstract}
Fighting becomes a problem in social life, which can be categorized as juvenile delinquency. The issue of juvenile delinquency in society is currently increasing, this causes unrest in the community. The environment, place of residence, and friends in relationships have a big influence on the formation of identity and self-development. Juvenile delinquency needs to be addressed and prevention efforts need to be done, this is necessary to avoid wider impacts that can threaten the security of the community. By using juvenile delinquency theory according to Dr. Kartini Kartono in examining the forms of juvenile delinquency and the prevention of juvenile delinquency. Researchers used the Dis-programming design method for combining several programs according to community needs.
\end{abstract}

Keywords: juvenile deliquency; third place

\section{PENDAHULUAN}

\section{Latar Belakang}

Jakarta Timur memiliki jumlah tawuran terbanyak, namun sekarang banyak remaja yang menganggap tawuran sebagai hiburan. Tawuran yang dianggap sebagai salah satu hiburan pun juga menandakan kurangnya ruang bermain publik yang di butuhkan, sehingga pelampiasan yang di gunakan adalah tawuran. Secara psikologis, kenakalan remaja merupakan wujud dari konflik-konflik yang tidak terselesaikan dengan baik pada masa kanak-kanak maupun remaja.

Pada media banyak sekali ditemukan kenakalan remaja yang terjadi, seperti perkelahian remaja, pembunuhan antar teman, penyebaran narkoba, minuman keras, pencurian yang dilakukan olah anak-anak, dan kasus kehaminal di luar nikah yang banyak terjadi dikalangan remaja. 
Pelanggaran dalam norma masyarakat seperti pelanggaran status dan pelanggaran terhadap hukum pidana yang terjadi di kalangan masyarakat. Menurut KPAI (2018) sejak tahun 20112018, tercatat sebanyak 11.116 anak di Indonesia yang terangkut dengan kasus kriminal. Sebanyak 4.869 kasus telah tercatat pada tahun 2018, dengan angka paling besar 1.434 kasus Anak Berhadapan Hukum (ABH), kemudian 841 kasus keluarga dan pengasuhan alternatif, dan 679 kasus pornografi dan cyber crime, ketiga kasus tersebut menempati 3 teratas dalam kasus pengaduan yang di terima oleh Komisi Perlindungan Anak (KPAI).

\section{Rumusan Permasalahan}

Adapun rumusan masalah dalam perancangan Sarana Olahraga Interaktif di Jatinegara adalah:

(1.) Pada era ini kenakalan remaja semakin marak terjadi. Mengapa isu kenakalan remaja menjadi semakin marak di lingkungan?

(2.) Terdapat beberapa cara dalam penanganan isu kenakalan remaja. Usulan program yang di sarankan untuk mengurangi isu kenakalan remaja?

(3.) Arsitektur memegang peran penting dalam perencanaan dan perancangan perkotaan. Hal yang dapat dilakukan oleh arsitektur untuk menanggapi maraknya isu kenakalan remaja?

\section{Tujuan}

Penelitian ini bertujuan untuk menyalurkan aspirasi, emosi, ekspresi, dan imajinasi yang baik. Membantu dalam pencarian jati diri para remaja, serta membuat lingkungan masyarakat yang positif serta sehat.

\section{KAJIAN LITERATUR}

\section{Open Architecture for Third Place}

Open Architecture merupakan sebuah sistem yang terbuka dan mampu beradaptasi dengan kepentingan tertentu. Open Architecture sendiri dapat menjadi platform yang dapat dikombinasikan berdasarkan kondisi masyarakat perkotaan Jakarta atau kota besar lainnya.

Third Place menurut Oldenburg (2000), mengidentifikasi "Third Place" sebagai ruang publik dimana orang-orang dapat berkumpul dan berinteraksi. Third Place sendiri menjadi wadah secara sukarela, tidak formal, dan dengan senang berpatisipasi dengan perkumpulan untuk tiap individu diluar dari rumah dan tempat bekerja, dan ditandai dengan suasana hati yang senang. Open Architecture For Third Place, dapat melihat hal-hal penting yang terkait dengan konteks kebutuhan masyarakat kota dan modernitas yang berorientasi pada teknologi, informasi, dan individu. Namun pada era saat ini, banyak masyarakat kota modern memiliki ciri individualistis dan lebih sensitif terhadap personal space-nya, hal ini membuat perbedaan publik-privat menjadi rancu. Pembagian ruang merupakan wujud dari privat, dinding menjadi penyataan ruang, namun dalam hal Open Architecture For Third Place, konflik public-privat ini menjadi hal unik yang berpotensi untuk dikembangkan.

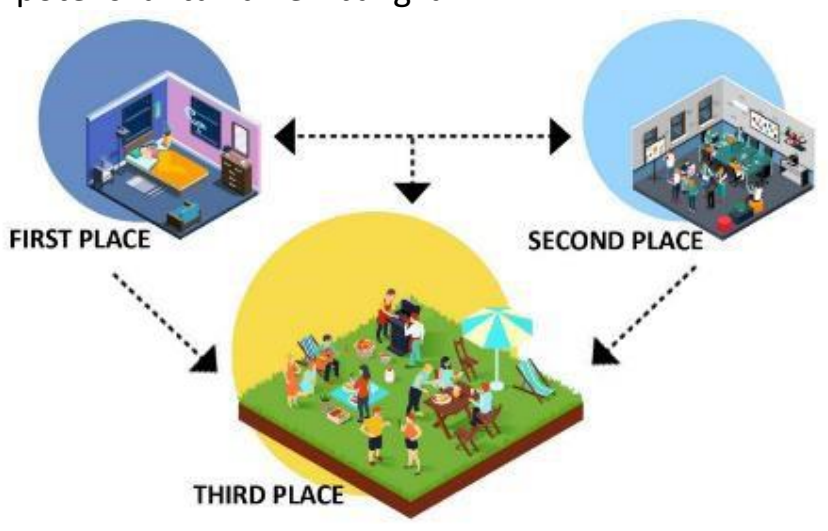

Gambar 1. Skema terjadinya Third Place

Sumber: Monica, 2020 
Pada saat ini kepadatan bangunan di kota Jakarta sudah semakin meningkat, kebutuhan sehari-hari pun meningkat terkadang mengerjakan satu pekerjaan saja tidak cukup, banyak orang memiliki pekerjaan sampingan di luar dari pekerjaan utamanya, sehingga banyak orang terjebak dengan aktifitas yang membuatnya jenuh, menjadi lebih individualis, dan lebih sensitif. Third Place sudah ada sejak dahulu, namun pada masa kini Third Place sendiri mulai kehilangan arti sesungguhnya karena didominasi oleh komersial. Adapun kegunaan dari Third Place adalah : (a.) Untuk pengalaman pribadi. (b.) Untuk memenuhi kebutuhan pribadi. (c.) Menjelaskan siapa kita dan apa yang kita kerjakan. (d.) Berfungsi secara pribadi. (e.) Ada disaat kita membutuhkannya (Kartono, 2003).

Berikut ini hal yang harus diperhatikan dalam Open Architecture For Third Place yang baik, yaitu: (1.) Netral, Third Place harus dibuat aman dan nyaman tanpa memandang status dan kelas. (2.) Level, dalam Third Place posisi atau jabatan yang menandakan status sosial harus di hilangkan. (3.) Conversation, sebuah Third Place harus dapat membuat orang-orang berinteraksi satu sama lain membuat percakapan yang menyenangkan dan dapat dinikmati oleh semua orang dari semua kalangan umur. (4.) Accessibility and Accommodation, sebuah Third Place harus memiliki pencapaian yang mudah. (5.) Regulars, sebuah Third Place dibuat agar dapat memancing orang-orang untuk datang secara rutin dengan membuat program yang sesuai kebutuhan. (6.) Plain and Unpretentious, membuat Third Place sebagai tempat yang nyaman untuk bersosialisasi. (7.) Playful, membuat sebuah Third Place yang dapat di datangi oleh segala kalangan dan segala umur, mengandung unsur kesenangan (Kartono, 2003).

\section{Kenakalan Remaja}

Juvenile Delinquency (juvenilis = muda, bersifat kemudaan; delinquency dari delinqucuere = jahat, durjana, pelanggar, nakal) ialah anak-anak muda yang selalu melakukan kejahatan, dimotivasi demi mendapatkan perhatian, status sosial dan penghargaan dari lingkungannya (Kartono, 2003). Berikut ini merupakan bentuk dari kenakalan remaja: (1.) Kenakalan Remaja Terisolir (Delinquency Terisolir), pada umumnya remaja dengan kategori kenakalan ini tidak menderita kerusakan psikologis. (2.) Kenakalan Remaja Neurotik (Delinquency Neurotik), kenakalan remaja kategori ini menderita gangguan kejiwaan yang cukup serius, berupa kecemasan, merasa selalu tidak aman, merasa bersalah dan lain sebagainya. (3.) Kenakalan Remaja Psikotik (Delinquency Psikopatik), kenakalan remaja dengan kategori ini sedikit jumlahnya, akan tetapi jika dilihat dari segi keamanan, kenakalan remaja ini merupakan oknum kriminal yang paling berbahaya. (4.) Kenakalan Remaja Defek Moral (Delinquency Defect Moral), Kenakalan remaja defek moral mempunyai ciri selalu melakukan tindakan anti sosial, walaupun pada dirinya tidak terdapat penyimpangan, namun ada disfungsi pada intelegensinya (Kartono, 2003).

Terdapat pula cara untuk menggulangi kenakalan remaja dengan tindakan preventif dan kuratif. Tindakan preventif yang dilakukan antara lain : (1.) Meningkatkan kesejahteraan keluarga. (2.) Perbaikan lingkungan, yaitu daerah rawan kampung-kampung miskin. (3.) Menyediakan tempat rekreasi yang sehat bagi remaja. (4.) Membentuk badan kesejahteraan anak-anak. (5.) Mendirikan tempat latihan untuk menyalurkan kreativitas para remaja delikuen dan yang non delikuen. Selanjutnya tindakan kuratif yang dilakukan antara lain: (1.) Menghilangkan semua sebab timbulnya kejahatan remaja, baik yang berupa pribadi, keluarga, sosial ekonomis, dan kultural. (2.) Memindahkan anak-anak nakal ke tengah lingkungan sosial yang lebih baik. (3.) Memperbanyak lembaga latihan kerja dengan program kegiatan pembangunan. (4.) Mendirikan klinik psikologi untuk meringankan dan memecahkan konflik emosional dan gangguan kejiwaan lainnya. Memberikan pengobatan medis dan terapi psikoanalitis bagi mereka yang menderita gangguan kejiwaan (Kartono, 2003). 


\section{Kriteria Struktur dan Bentuk Kota Yang Berkelanjutan}

Proyek ini menggunakan acuan perancangan Sarana Olahraga Interaktif di Jatinegara berdasarkan struktur dan bentuk kota yang berkelanjutan dan kebutuhan kotanya menurut Hirarchi Maslow (Hildebrand Frey, 1999).

Tabel 1. Kriteria dan Struktur Bentuk Kota yang Berkelanjutan

\begin{tabular}{|c|c|c|}
\hline $\begin{array}{c}\text { Kebutuhan Mns } \\
\text { (Maslow's hierarchy) }\end{array}$ & Kriteria untuk kota baik & $\begin{array}{c}\text { Kriteria untuk kota dan daerah } \\
\text { yang berkelanjutan }\end{array}$ \\
\hline $\begin{array}{l}\text { 1. Satu lingkungan } \\
\text { sosial yang kondusif } \\
\text { 2. Kesan, reputasi yang } \\
\text { baik dan prestisius } \\
\text { 3. Ada kesempatan } \\
\text { untuk berbuat } \\
\text { kreatif }\end{array}$ & $\begin{array}{l}\text { - Tempat dimana orang } \\
\text { memiliki penghasilan dan } \\
\text { anak-anak dapat } \\
\text { bermain/bersosialisasi } \\
\text { - } \quad \text { Merasa sebagai bagian dari } \\
\text { masyarakat yang ada } \\
\text { dikawasan tsb. } \\
\text { - Tempat yang dapat memberi } \\
\text { rasa percaya diri yang kuat. } \\
\text { Tempat yang dapat memberi } \\
\text { status dan martabat } \\
\text { Kesempatan bagi individual } \\
\text { membentuk ruang-ruang } \\
\text { private } \\
\text { Kesempatan bagi } \\
\text { mastarakatnya membentuk } \\
\text { kawasan dan lingkungannya } \\
\text { sendiri }\end{array}$ & $\begin{array}{l}\text { KONDISI SOSIAL EKONOMI } \\
\text { - } \quad \text { Masyarakat campuran } \\
\text { - } \\
\text { - } \\
\text { Derajat ekonomi daerah } \\
\text { sendiri }\end{array}$ \\
\hline $\begin{array}{l}\text { 4. Nilai estetika dan } \\
\text { lingkungan yang } \\
\text { menyenangkan }\end{array}$ & $\begin{array}{l}\text { - Tempat yang didesain secara } \\
\text { estetis tinggi dan } \\
\text { menyenangkan } \\
\text { - } \quad \text { Tempat yang secara fisik dapat } \\
\text { memberi image tersendiri } \\
\text { - Kota yang merupakan tempat } \\
\text { budaya dan karya seni }\end{array}$ & $\begin{array}{l}\text { KUALITAS VISUAL SECARA } \\
\text { FORMAL } \\
\text { - } \quad \text { Tingkat imajinasi kota } \\
\text { - } \quad \text { Penciptaan suatu rasa yang } \\
\text { memusat dan tempsat yang } \\
\text { bermakna }\end{array}$ \\
\hline
\end{tabular}

Sumber : Hildebrand Frey, 1999

\section{METODE}

\section{Metode Dis-Programming}

Penerapan Dekontruksi dalam arsitektur, selalu terkait dengan konsep, konteks, dan program. Ketiga hal tersebut memiliki hubungan timbal balik, saling bertentangan, ataupun saling mengabaikan(Tshumi, 1987). Ketiga konsep tersebut dibagi menjadi, Cross-Programming, Trans-Programming, dan Dis-Programming. Peneliti menggunakan metode perancangan Disprogramming dengan mengkombinasikan dua program sehingga konfigurasi spesial program A mengkontaminasi program dan konfigurasi spasial program B (Derrida, 1967).

\section{Metode Komparatif}

Metode komparatif, membandingkan persamaan serta perbedaan beberapa kelompok terhadap subjek penelitian. Berikut ini merupakan subjek perbandingan yang dilakukan yaitu: (1.) Dmytro Aranchii Architects, Signature Garden, merupakan taman interaktif dengan skala besar yang terdapat di Kyiv, Ukraine. Dengan luas $6000 \mathrm{~m}^{2}$ taman ini terletak di atas pusat perbelanjaan dan menyediakan ruang bagi para pengunjung untuk makan, bermain, dan menikmati vegetasi dan fitur air yang sudah di sediakan. (2.) .TEMU Coffee Seminyak, Bali, Terdapat area teater di bagian belakang Titik Temu Coffee, area ini merupakan ikon interior Titik Temu Coffee. Dengan tangga kayu seperti kursi teater, serta terdapat taman outdoor yang dilengkapi bean bag untuk bersantai. (3.) Oasis Terraces, merupakan sebuah pusat 
lingkungan dan poliklinik di Punggol, Singapore. Bangunan ini memiliki fasilitas kesehatan, program taman komunal, ruang bermain, gymnasium, ruang ritel, ruang makan, dan ruang belajar, dengan harapan semuanya akan menjadi satu sebagai generasi baru pembangunan terintegrasi.

\section{DISKUSI DAN HASIL}

\section{Penerapan Teori}

Third-place memiliki beberapa karakteristik yakni bersifat netral, dapat menjadi identitas bagi masyarakat sekitar, dan juga dapat meningkatkan pengalaman fisik dan psikologis bagi para pengunjung. Jatinegara memiliki sebuah potensi yang dapat dimanfaatkan sebagai sarana olahraga interaktif, hal ini dikarenakan jumlah tawuran yang cukup banyak. Sarana olahraga interaktif ini dapat menjadi identitas bagi masyarakat di Jatinegara, dengan meningkatkan pengalaman fisik dan psikologis masyarakat di Jatinegara (dengan pembentukkan program berdasarkan hasil dari kondisi first-place dan second-place).

\section{Program Ruang}

Program ruang pada proyek Sarana Olahraga Interaktif di Jatinegara memiliki sarana olahraga sebagai fungsi utama, dan didukung oleh ruang serbaguna, sebagai pemenuhan kebutuhan masyarakat sekitar. Berikut ini merupakan penjelasan program yang menjadi daya tarik utama:

(a.) Taman Interaktif, Sebuah ruang publik yang berfungsi untuk interaktif warga kota, serta mewadahi kegiatan individu maupun kelompok yang dilakukan dalam taman. Dalam perancangan Taman Interaktif yang dilakukan adalah mengutamakan fungsi taman sebagai area hijau perkotaan yang sekaligus berfungsi mengakomodasi kegiatan interaksi sosial antar warga sekitarnya. Taman Interaktif ini diharapkan dapat mewadahi seluruh kegiatan interaksi sosial masyarakat. Fasilitas yang disediakan mengandung unsur rekreasi dan edukasi yang dapat memancing warga untuk berinteraksi dalam area taman.

(b.) Olahraga Interaktif, Sebuah tempat untuk melakukan olah raga yang dapat dilakukan secara beramai-ramai untuk berinteraksi sosial antar warga, seperti futsal, bola basket, bulu tangkis, tennis, dll. Dengan program ini keselarasan, rasa sportifitas dan kebersamaan dapat timbul di kalangan para remaja.

(c.) Lapangan Serbaguna, Sebuah lapangan yang memiliki multifungsi untuk menampung beberapa kegiatan outdoor yang membutuhkan space cukup besar, seperti permainan bola basket, futsal, karate, takwondo, dll. Berikut ini merupakan pembagian persentase program ruang.

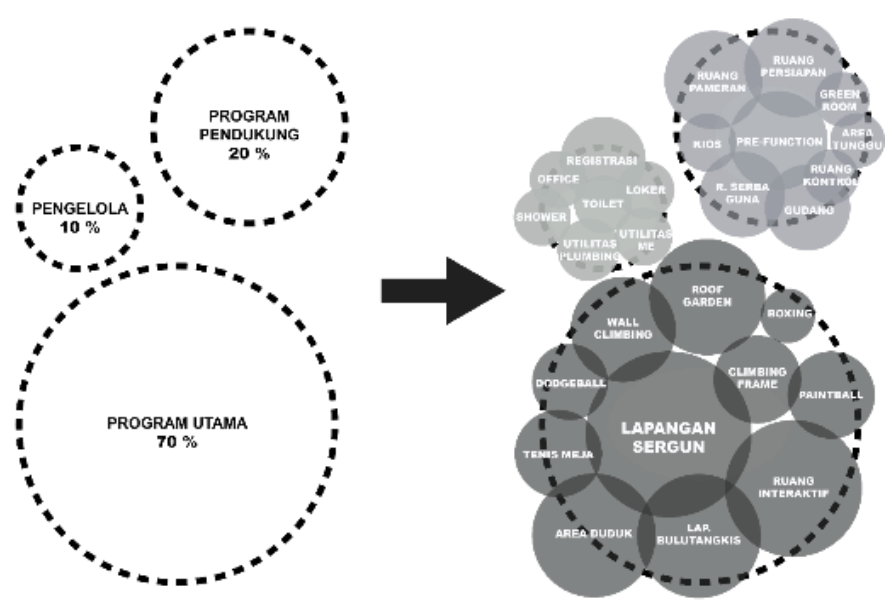

Gambar 2. Diagram Program Ruang

Sumber : Monica, 2020 
Berikut ini merupakan perkiraan program ruang secara rinci:

Tabel 2. Tabel Program Ruang

\begin{tabular}{|c|c|c|c|c|c|c|}
\hline Nama Ruang & Deskripsi ruang & Kapasitas & Sumber & $\mathrm{Jml}$ & Sirkulasi & Luas Total \\
\hline Lobby & Lobby & 100 org & DA & 1 unit & $40 \%$ & $200 \mathrm{~m}^{2}$ \\
\hline \multirow{5}{*}{ Area Pengelola } & Registrasi & 6 org & DA & 3 unit & $20 \%$ & \multirow{5}{*}{$605,6 \mathrm{~m}^{2}$} \\
\hline & Loker & 60 org & HDP & 2 unit & $20 \%$ & \\
\hline & Shower & $15 \mathrm{org}$ & HDP & 2 unit & $20 \%$ & \\
\hline & Toilet & 5 org & DA & 2 unit & $20 \%$ & \\
\hline & R. Security & 5 org & DA & 1 unit & $20 \%$ & \\
\hline \multirow{15}{*}{ Fasilitas Indoor } & Kios & 2 org & & 9 unit & $20 \%$ & \multirow{15}{*}{$2.579,3 \mathrm{~m}^{2}$} \\
\hline & Area Duduk & 20 org & $\mathrm{DA}$ & 1 unit & $20 \%$ & \\
\hline & Pre-function & 50 org & $\mathrm{DA}$ & 1 unit & $20 \%$ & \\
\hline & R. Serbaguna & 100 org & $\mathrm{DA}$ & 1 unit & $20 \%$ & \\
\hline & Green Room & 10 org & $\mathrm{DA}$ & 2 unit & $20 \%$ & \\
\hline & R. Kontrol & 5 org & $\mathrm{DA}$ & 1 unit & $20 \%$ & \\
\hline & Ruang Persiapan & 10 org & DA & 2 unit & $20 \%$ & \\
\hline & Area Tunggu & 20 org & & 1 unit & $20 \%$ & \\
\hline & Gudang & & AP & 1 unit & $20 \%$ & \\
\hline & R.interaktif & 10 org & & 1 unit & $20 \%$ & \\
\hline & Dodgeball & 10 org & NDL & 1 unit & $20 \%$ & \\
\hline & Paintball & 10 org & & 1 unit & $20 \%$ & \\
\hline & Lapangan Bulutangkis & 4 org & PBSI & 3 unit & $20 \%$ & \\
\hline & Boxing & 30 org & PPKBI & 1 unit & $20 \%$ & \\
\hline & Tennis Meja & 2 org & PTMSI & 4 unit & $20 \%$ & \\
\hline \multirow{4}{*}{$\begin{array}{l}\text { Fasilitas } \\
\text { Outdoor }\end{array}$} & Lapangan Serbaguna & 16 orang & PERBASI & 1 unit & $20 \%$ & \multirow{4}{*}{$1.258,2 \mathrm{~m}^{2}$} \\
\hline & Wall Climbing & 20 org & DA & 1 unit & $20 \%$ & \\
\hline & Climbing Frame & 10 org & & 1 unit & $20 \%$ & \\
\hline & Roof Garden & 50 org & & 1 unit & $20 \%$ & \\
\hline \multirow{8}{*}{ Utilitas } & STP & 400 org & DINAS PU & 1 unit & $20 \%$ & \multirow{8}{*}{$376,8 \mathrm{~m}^{2}$} \\
\hline & GWT & 400 org & DINAS PU & 1 unit & $20 \%$ & \\
\hline & R. Pompa & & DA & 1 unit & $20 \%$ & \\
\hline & Genset & & DINAS PU & 1 unit & $20 \%$ & \\
\hline & Trafo & & DA & 1 unit & $20 \%$ & \\
\hline & Panel & & DA & 1 unit & $20 \%$ & \\
\hline & R. Bahan Bakar & & DA & 1 unit & $20 \%$ & \\
\hline & Reservoir Atas & & $\mathrm{DA}$ & 1 unit & $20 \%$ & \\
\hline
\end{tabular}

Sumber : Monica, 2020

\section{Proses Gubahan Massa}

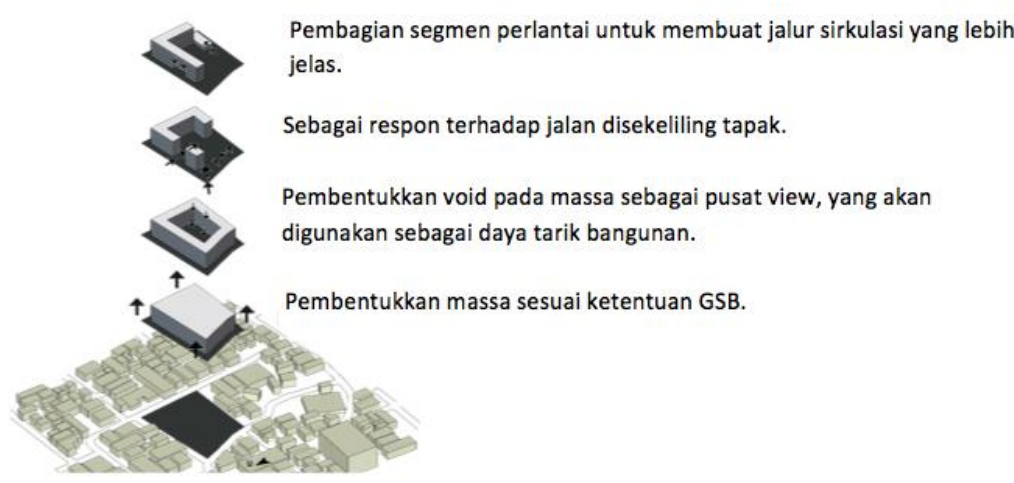

Gambar 3. Gubahan Massa

Sumber : Monica, 2020 


\section{Zonasi Bangunan}

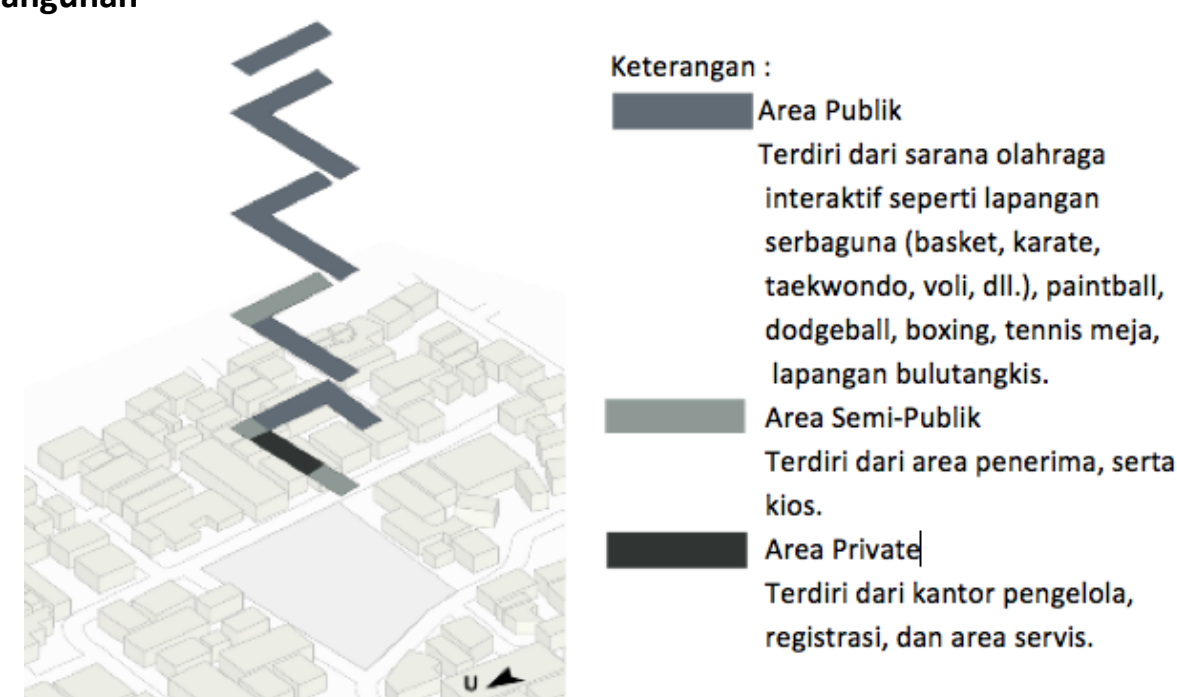

Gambar 4. Diagram Zonasi Ruang

Sumber : Monica, 2020

\section{Konsep}

Konsep desain yang dihadirkan dalam proyek ini menghadirkan sebuah sarana yang memungkinkan para pengunjung untuk berinteraksi satu sama lain, selain itu pada proyek ini menghadirkan unsur terbuka sehingga siapa saja dapat datang.

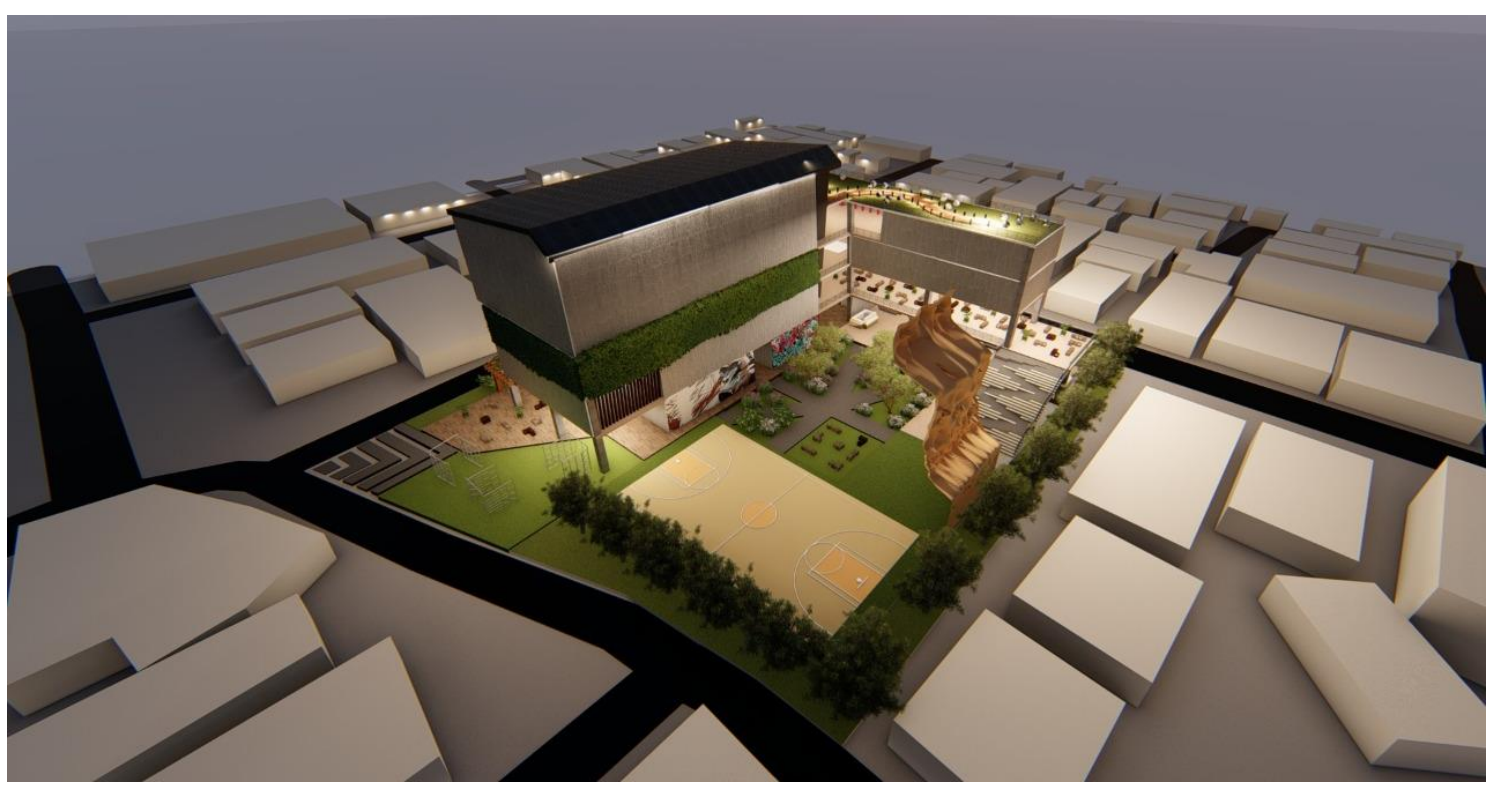

Gambar 5. Penerapan Unsur Terbuka Pada Proyek

Sumber : Monica, 2020

Pada area lantai 2 menjadi ruang terbuka untuk warga saling berinteraksi, dengan view menghadap ke arah lapangan serbaguna, wall climbing, dan taman. Ruang berkumpul ini memiliki banyak tempat duduk tanpa dibatasi oleh dinding agar menjadi tempat yang nyaman untuk berkumpul, dan bersantai. 


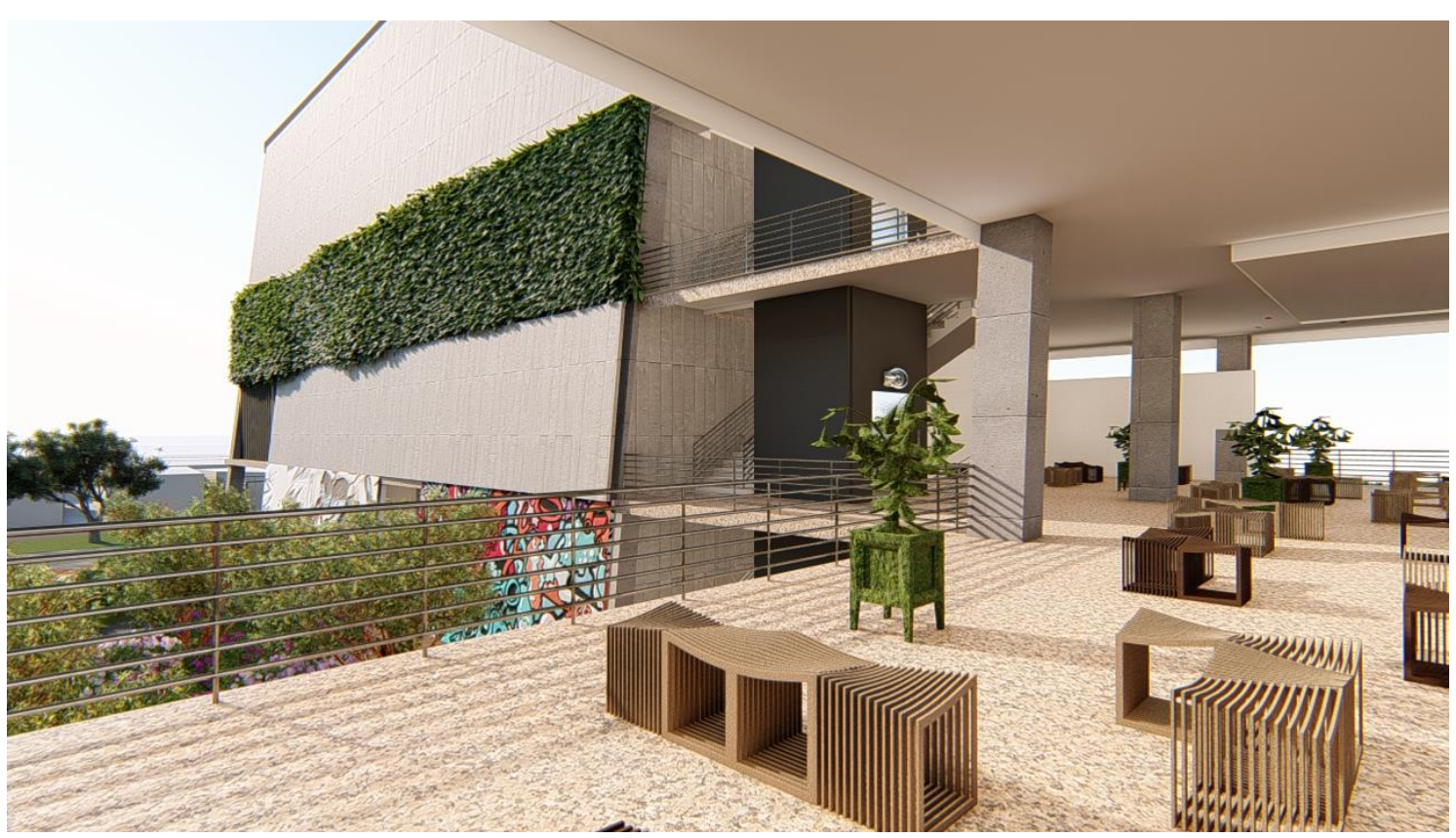

Gambar 6. Ruang Berkumpul dan Berinteraksi Sumber : Monica, 2020

Berikut ini merupakan suasana eksterior bangunan :

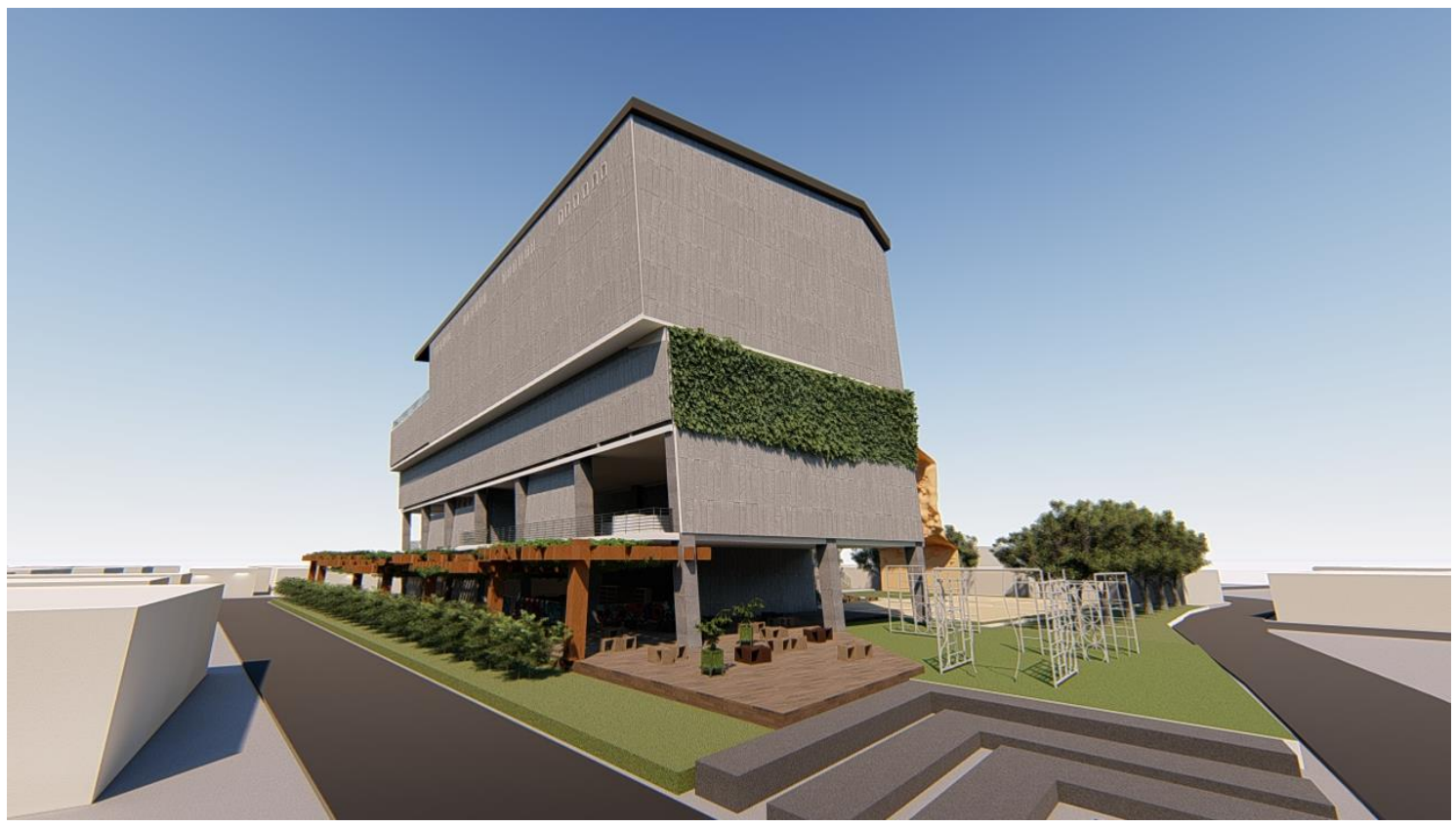

Gambar 7. Eksterior Bangunan Dari Arah Jalan Utama Sumber : Monica, 2020 


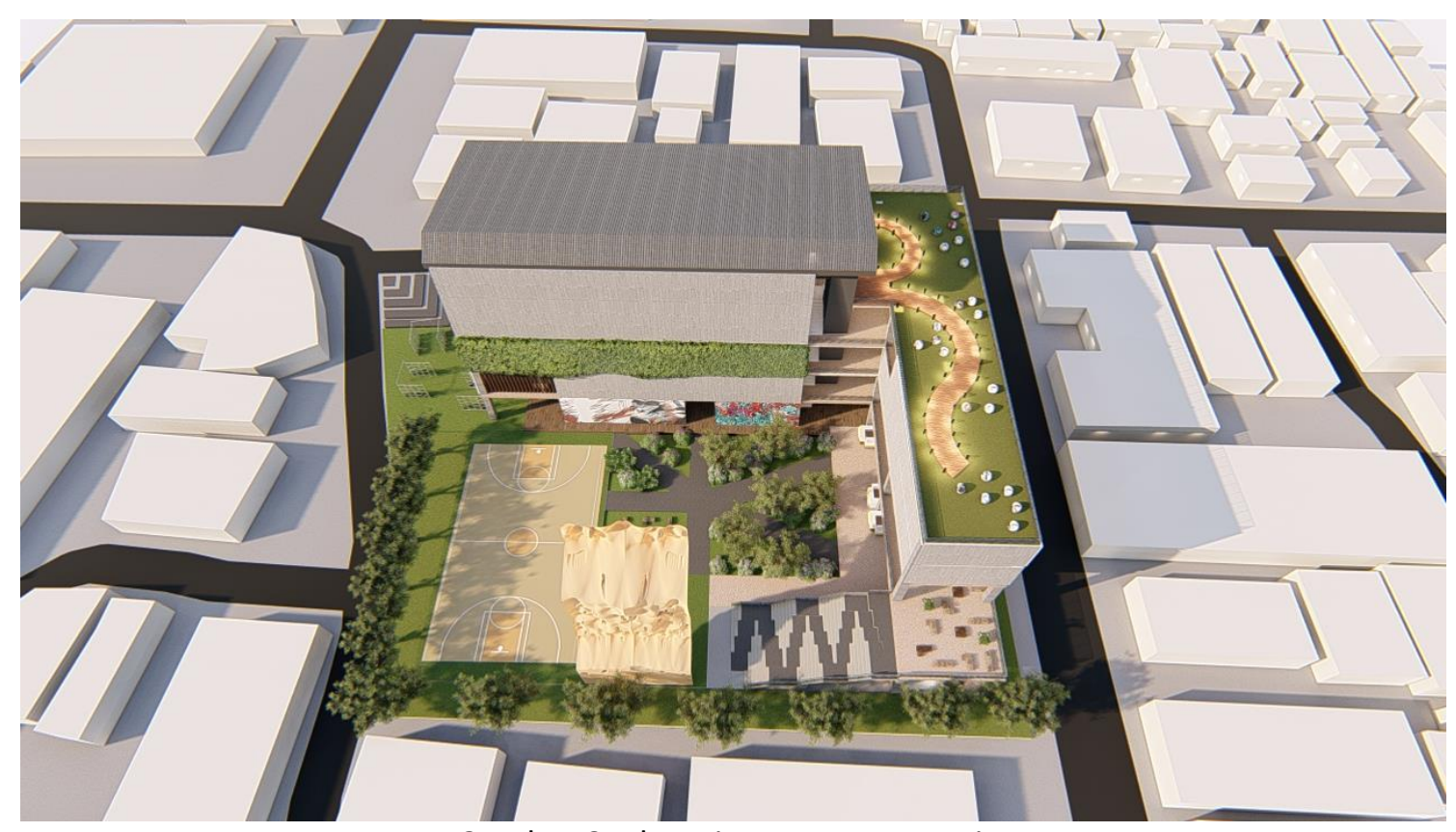

Gambar 8. Eksterior Bangunan Dari Atas

Sumber : Monica, 2020

\section{KESIMPULAN DAN SARAN} Kesimpulan

Sarana Olahraga Interaktif di Jatinegara merupakan sebuah titik temu antara first place dan second place, yang menjadi jawaban atas permasalahan yang terjadi di masyarakat untuk menciptakan keadaan yang aman dan nyaman bagi masyarakat. Sarana Olahraga Interaktif di Jatinegara menjadi sebuah wajah baru bagi masyarakat Jatinegara dengan mengatasi permasalahan di Jatinegara yang awalnya memiliki titik tawuran terbanyak, dengan sarana olahraga sebagai program utama dan didukung oleh ruang serbaguna sebagai program pendukung, pada proyek ini program interaktif sendiri meliputi kegiatan olahraga yang melibatkan pemain lebih dari 2 orang atau lebih, atau sebuah ruang yang menjadi wadah tempat masyarakat berkumpul untuk saling bersosialisasi. Program-program ini terbentuk berdasarkan permasalahan yang terjadi di masyarakat Jatinegara.

\section{Saran}

Third place menjadi sebuah wadah yang dapat mengatasi isu atau permasalahan yang terjadi di sekitar masyarakat, dengan ini arsitekturpun dapat membantu mengatasi permasalahan di masyarakat.

\section{REFERENSI:}

Badan Pusat Statistik. 2019. Statistik Kriminal 2019. Jakarta: BPS

Eko, S. (2015). Panduan SDGs. [Electronic version]. Jakarta: International NGO forum on Indonesian Development.

Karlina, L. (2020). Fenomena Terjadinya Kenakalan Remaja. Jurnal Edukasi Non-fornal, 1(2), 147-158.

Sumara, D. S., Humaedi, S., \& Santoso, M. B. (2017). Kenakalan remaja dan penanganannya. Jurnal Prosiding Penelitian \& PKM, 4(2).

Unayah, N., \& Sabarisman, M. (2015). Fenomena kenakalan remaja dan kriminalitas.jurnal Sosio informa, 1(2). 
https://www.wawasanpendidikan.com/2015/02/Faktor-Faktor-yang-Menyebabkan-

Kenakalan-Remaja-dari-Berbagai-Aspek.html. Diakses: 4 Februari 2020

https://nasional.sindonews.com/read/1386542/13/tindak-kriminalitas-anak-sangat-

Memprihatinkan-1552524624. Diakses: 7 Februari 2020

https://www.kemenpppa.go.id/index.php/page/read/31/1405/tawuran-bentuk-kesalahan-

remaja-dalam-bereksistensi. Diakses: 7 Februari 2020

https://www.archdaily.com/877062/dmytro-aranchii-architects-constructs-interactive-park-

on-top-of-shopping-center/5983940cb22e382015000094-dmytro-aranchii-architects-

constructs-interactive-park-on-top-of-shopping-center-image?next_project=no. Diakses:

15 Februari 2020

https://www.archdaily.com/928687/ireading-cultural-space-

hypersity?ad_source=search\&ad_medium=search_result_projects. Diakses: 15 Februari 2020

https://journal.sociolla.com/lifestyle/temu-coffee-seminyak/. Diakses: 15 Februari 2020 